\title{
Annealing atmosphere influence on contact resistivity of ohmic Pd/Ge/Au contact to n-GaAs
}

\author{
D. M. Mitin ${ }^{1}$, F. Yu. Soldatenkov ${ }^{1}$, A. M. Mozharov², A. A. Vasil'ev², V. V. Neplokh², I. S. Mukhin ${ }^{2,3}$ \\ ${ }^{1}$ Ioffe Physical Technical Institute of the Russian Academy of Sciences, \\ Politekhnicheskaya, 26, St. Petersburg, 194021, Russia \\ ${ }^{2}$ Saint Petersburg National Research Academic University of the Russian Academy of Sciences, \\ Khlopina, 8, building 3, lit. A, St. Petersburg, 194021, Russia \\ ${ }^{3}$ Saint Petersburg National Research University of Information Technologies, Mechanics and Optics, \\ Kronverkskiy, 49, St. Petersburg, 197101, Russia \\ mitindm@mail.ru, f.soldatenkov@mail.ioffe.ru,mozharov@spbau.ru,ftf.vasiliev@yandex.ru, \\ vneplokh@spbau.ru,imukhin@yandex.ru
}

\begin{abstract}
We report the results of research for the $\mathrm{Pd} / \mathrm{Ge} / \mathrm{Au}$ ohmic contact resistivity to $\mathrm{n}$-GaAs thermally treated in various gas atmospheres at low temperature. The lowest contact resistivity of about $4 \cdot 10^{-6} \Omega \cdot \mathrm{cm}^{2}$ was obtained with annealing under a hydrogen atmosphere. The mechanism of the ohmic contact formation upon annealing under a hydrogen atmosphere has been proposed. The achieved results can be used for development of multi-junction solar cells, power semiconductor devices, lasers, and nanowire-based structures sensible to a high temperature treatment.
\end{abstract}

Keywords: GaAs, ohmic contact, contact resistivity, thermal annealing, solid-phase regrowth.

Received: 8 November 2018

\section{Introduction}

Ohmic contact $(\mathrm{OC})$ to $\mathrm{n}-\mathrm{GaAs}$ is typically achieved with fabrication of multiple cladding $\mathrm{Au} / \mathrm{Ni} / \mathrm{Au}: \mathrm{Ge}$ or $\mathrm{Au} / \mathrm{Ni} / \mathrm{Au}$ :Ge/Ni layers during a short time interval (1-3 min). The $\mathrm{Au} / \mathrm{Ni} / \mathrm{Au}: \mathrm{Ge}$ contact is remarkable for its low contact resistivity of $10^{-6} \Omega \cdot \mathrm{cm}^{2}$ and high chemical stability [1,2]. However, this contact has limited applications, mainly due to a non-homogenous redistribution of the contact alloy components in liquid eutectic phase during thermal annealing. This negatively affects the contact morphology, contact resistivity distribution over the sample surface, and reproducibility of the ohmic contact fabrication process. Au-Ge contacts are also reported to lack thermal stability at device operating temperatures [1]. As an alternative solution, $\mathrm{Au}-\mathrm{Si}, \mathrm{Ti} / \mathrm{Pt} / \mathrm{Au}, \mathrm{Ge}-\mathrm{Cu} \mathrm{u}_{3}$, and other compounds were developed, which partly solve the problems of thermal stability, surface morphology and in some cases allow to avoid use of precious metals in the contact composition [3]. Still, these solutions have a limited application in the GaAs device fabrication technology.

At the end of 20-th century, a solid-phase crystal regrowth method was developed for fabrication of contacts to $\mathrm{n}$ - and p-GaAs [4-6]. One of the appropriate solutions for $\mathrm{n}-\mathrm{GaAs}$ contacts is $\mathrm{Pd} / \mathrm{Ge} / \mathrm{Au}$, allowing fabrication of planar ohmic contacts with good electrophysical properties [7]. In the years following the appearance of this OC, several papers on solid-phase crystallization mechanism, optimal cladding thicknesses, and corresponding times and maximum temperatures of the thermal annealing processes were published $[8,9]$. The highest quality of this OC is attributed to [9], where resistivity as low as $10^{-6} \Omega \cdot \mathrm{cm}^{2}$ by employing nitrogen atmosphere is reported. Meantime, few publications exist, which address the question of gas atmosphere influence on series resistivity during thermal annealing of $\mathrm{Pd} / \mathrm{Ge} / \mathrm{Au} \mathrm{OC}$, motivating the research reported here.

\section{Experimental}

To investigate the resistance of the studied alloy, we used $150 \mathrm{~nm}$ thick n-GaAs:Si structure with free electron density $\mathrm{N}_{D}=2 \cdot 10^{18} \mathrm{~cm}^{-3}$, grown on semi-insulating GaAs substrate. Each test sample has eight contact pads, located at various distances from each other (from 5 to $100 \mu \mathrm{m}$, Fig. 1) used for the resistivity measurements. The contact pads were fabricated with UV lithography using SUSS MicroTec (Germany) MJB4 setup. In order to suppress the current spreading during the measurements, all of the test samples were subjected to $\mathrm{H}_{2} \mathrm{SO}_{4}: \mathrm{H}_{2} \mathrm{O}_{2}: \mathrm{H}_{2} \mathrm{O}$ 1:1:20 wet etching solution to remove the doped GaAs layer. $200 \mathrm{~nm}$ thick layer was removed from the area surrounding the contact pads at a distance of more than $25 \mu \mathrm{m}$ (Fig. 1), thus revealing the GaAs substrate. 
The contact alloy deposition was performed using Boc Edwards (UK) Auto 500 setup at $5 \cot 10^{-7}$ mbar vacuum. Before the deposition the samples were treated with $\mathrm{HCl}: \mathrm{H}_{2} \mathrm{O} 1: 1$ solution for $15 \mathrm{~s}$ to remove the naturally oxidized GaAs layer.

$10 \mathrm{~nm} \mathrm{Pd}$ and $50 \mathrm{~nm}$ Ge layers were deposited using carbon sources heated with electron beam, $120 \mathrm{~nm} \mathrm{Au}$ was fabricated with thermal evaporation from a resistively heated molybdenum crucible. After the metal deposition the photoresist was removed with lift-off in dimethyl sulfoxide.

Part of the samples were thermally annealed in $\mathrm{N}_{2}$ or $\mathrm{H}_{2}$ atmosphere in Jipelec (France) Jetfirst 100 setup using $500 \mathrm{~cm}^{3} / \mathrm{min}$ gas flow. The other part of the samples was annealed in 1 mbar vacuum. All the test samples were annealed during the same time and temperature settings, namely 1 hour and $175{ }^{\circ} \mathrm{C}$. The samples' surface morphology before and after the annealing was controlled using optical microscopy. According to the experimental data, the morphology did not change dramatically after annealing at $175{ }^{\circ} \mathrm{C}$ in $\mathrm{N}_{2}, \mathrm{H}_{2}$ atmospheres or in vacuum, remaining smooth and without scratches or visible grains (Fig. 1a). Meanwhile, higher annealing temperature $\left(360^{\circ} \mathrm{C}\right)$ leads to distortion of the contact surface morphology (Fig. 1b).

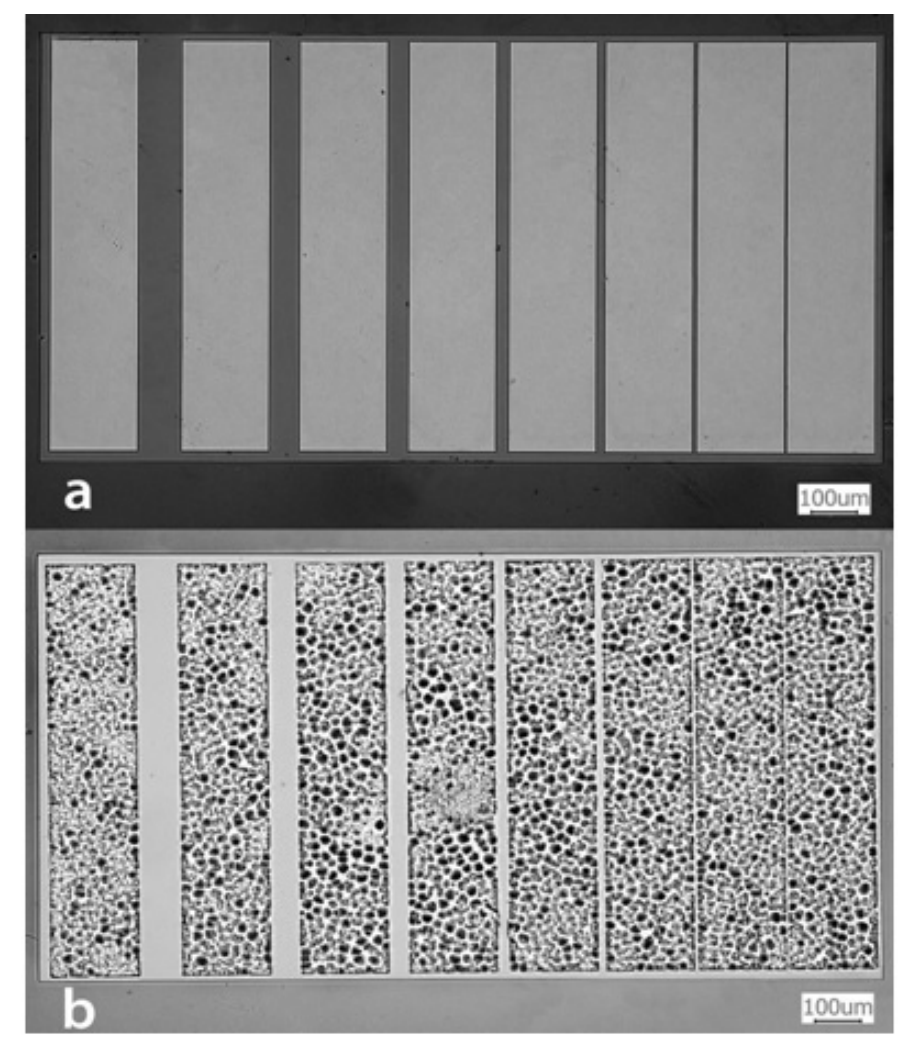

FIG. 1. Optical microscope image of the test sample surface with $\mathrm{Pd} / \mathrm{Ge} / \mathrm{Au}$ OC after annealing at $\mathrm{H}_{2}$ atmosphere at $175^{\circ} \mathrm{C}$ (a) and $360{ }^{\circ} \mathrm{C}($ b)

Contact resistivity $\rho_{c}$ of the studied $\mathrm{Pd} / \mathrm{Ge} / \mathrm{Au}$ contacts was calculated using transmission line method [10]. It includes measurement of the resistance $R_{T}$ and distance $L$ between the contact pads to draw $R_{T}(L)$ curves (Fig. 2). The experimental dots were approximated with a line, which crosses $R$ axis at doubled value of the contact resistance $R_{c}$ and $L$ axis at double negative value of the current spreading width $L_{w}$. The final contact resistivity value was calculated as follows:

$$
\rho_{c}=R_{c} \cdot L_{w} \cdot L_{c}
$$

where $L_{c}$ is the contact pad length. Deduced $R_{c}, L_{w}$ and calculated contact resistivity $\rho_{c}$ values are presented in Table 1.

\section{Results and discussion}

The lowest values for the contact resistance, current spreading width and contact resistivity $\left(4.15 \cdot 10^{-6} \Omega \cdot \mathrm{cm}^{2}\right)$ were achieved with annealing under $\mathrm{H}_{2}$. This value corresponds to the previously reported value of $2 \cdot 10^{-6} \Omega \cdot \mathrm{cm}^{2}$, 


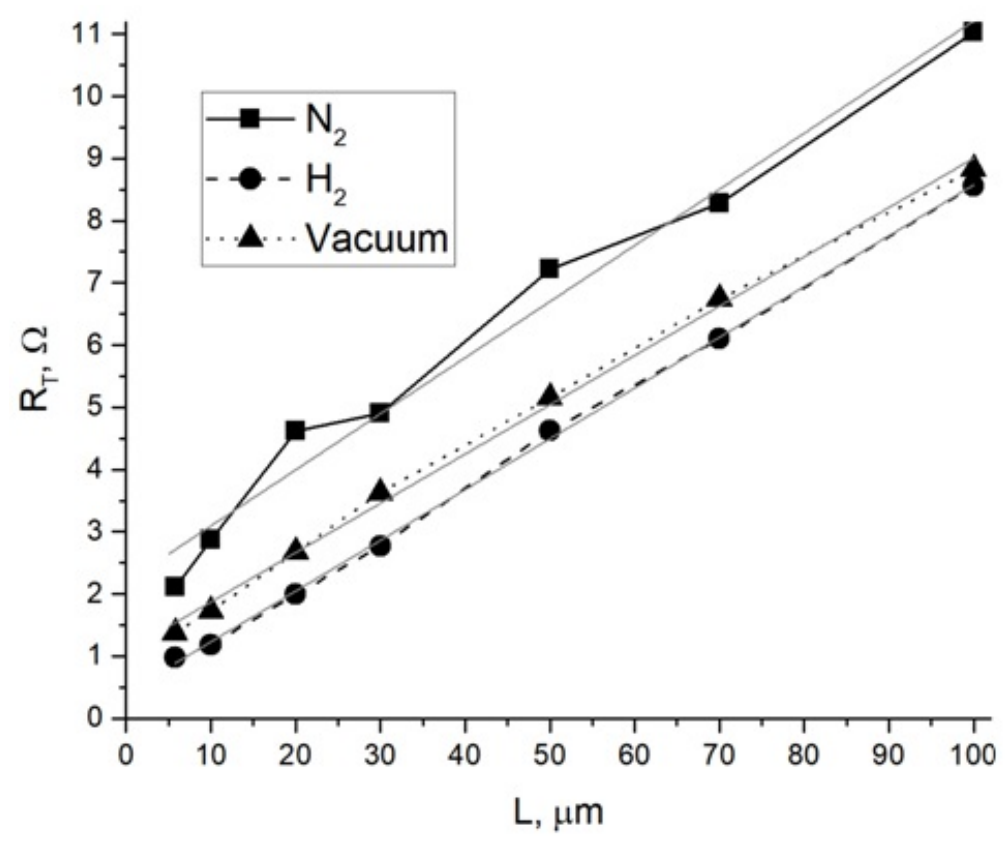

FIG. 2. Experimental dependence (dots) of resistance $R_{T}$ from the distance $L$ between contact pads. Gray lines represent linear approximations

TABLE 1. $n-\mathrm{GaAs} / \mathrm{Pd} / \mathrm{Ge} / \mathrm{Au}$ material system parameters

\begin{tabular}{|c|c|c|c|}
\hline Gas atmosphere & $R_{c}, \Omega$ & $L_{w}, \mu$ & $\rho_{c}, \Omega \cdot \mathrm{cm}^{2}$ \\
\hline $\mathrm{N}_{2}$ & 1.1 & 12.2 & $1.33 \cdot 10^{-4}$ \\
\hline $\mathrm{H}_{2}$ & 0.19 & 2.22 & $4.15 \cdot 10^{-6}$ \\
\hline Vacuum & 0.54 & 6.81 & $3.68 \cdot 10^{-5}$ \\
\hline
\end{tabular}

of $\mathrm{Pd} / \mathrm{Ge} / \mathrm{Au}$ OC annealed in $\mathrm{N}_{2}+\mathrm{H}_{2}$ atmosphere [8]. However, this result was obtained with the contacts deposited under ultra-high vacuum $\left(5 \cdot 10^{-8} \mathrm{mbar}\right)$.

Vacuum and nitrogen annealing led to about one and two orders of magnitude higher values of contact resistivity in comparison to hydrogen atmosphere, respectively.

Interpretation of the results requires further investigation of the contact region formation mechanism near the metal-semiconductor interface under different annealing conditions. We propose the following explanation for the observed discrepancy. Ge and Pd layers heating leads to formation of the solid solution. In the presence of hydrogen, the Pd layer absorbs gas molecules (this effect is especially pronounced at temperatures above $160{ }^{\circ} \mathrm{C}$, corresponding to $\mathrm{Pd}$ phase transition at atmospheric pressure). The diluted hydrogen molecules dissolve in Pd into atoms. The atomic hydrogen can reduce quantity of $\mathrm{Ga}_{2} \mathrm{O}_{3}$ formed due to surface oxidation of GaAs near the $\mathrm{Pd}$ contact providing crystallization of an epitaxial Ge layer from the $\mathrm{Pd}-\mathrm{Ge}$ solid solution [6] on the surface of GaAs. The latter effect in turn lowers the electric barrier for the charge carriers near the contact area facilitating low contact resistance.

It is worth noting that before the annealing all of the contacts were non-ohmic. An increase of the annealing temperature to $360{ }^{\circ} \mathrm{C}$ led to one order increase of the resistance value. Series resistance increase in this case can be explained with enhanced diffusion of $\mathrm{Au}$ and $\mathrm{Ge}$ into the GaAs near the interface, so that the solidphase recrystallization is superseded by eutectic reaction resulting in formation of Au:Ge solution typical for the $\mathrm{Au} / \mathrm{Ni} / \mathrm{Au}: \mathrm{Ge}$ contacts [7]. This process is accompanied by surface morphology distortion of the contact pads (Fig. 1b). 


\section{Conclusion}

In this report, we performed a series of experiments aimed at development of a fabrication method for low temperature $\mathrm{Pd} / \mathrm{Ge} / \mathrm{Au}$ ohmic contact to $\mathrm{n}-\mathrm{GaAs}$. The measurements have demonstrated that the fabricated contact is characterized with ohmic $\mathrm{I}-\mathrm{V}$ curve, low contact resistivity value and high conductivity of the contact material after annealing. The best results were achieved with $\mathrm{Pd} / \mathrm{Ge} / \mathrm{Au} \mathrm{OC}$ annealed in $\mathrm{H}_{2}$ atmosphere. This contact composition is suitable for fabrication of $\mathrm{OC}$ to semiconductor structures and susceptible to a high temperature annealing. The results are especially promising with respect to multi-junction solar cells [11] and nanowire optical devices [12]. The low values of the $\mathrm{Pd} / \mathrm{Ge} / \mathrm{Au}$ OC series resistance allowed us to increase the efficiency of the devices employing $\mathrm{n}$-GaAs due to the diminishing ohmic losses and enhanced collection of the charge carriers at the interface.

\section{Acknowledgement}

Authors thanks V.P. Ulin for helpful discussions of the results.

The work was supported by the Russian Science Foundation (grant No 17-79-30035).

\section{References}

[1] Baca A.G., Ren F., Zolper J.C., Briggs R.D., Pearton S.J. A survey of ohmic contacts to III-V compound semiconductors. Thin Solid Films, 1997, 309, P. 599-606.

[2] Kim T., Holloway P.H. Ohmic contacts to GaAs epitaxial layers. Crit. Rev. Solid State Mater. Sci, 1997, 22(3), P. $239-273$.

[3] Blank T.V., Gol'dberg Yu.A. Mechanisms of current flow in metal-semiconductor ohmic contacts. Semiconductors, 2007, 41(11), P. 12631292.

[4] Sands T., Marshall E.D., Wang L.C. Solid-phase regrowth of compound semiconductors by reaction-driven decomposition of intermediate phases. J. Mater. Res., 1988, 3(5), P. 914-921.

[5] Wang L.C. The Development of Solid Phase Regrowth on GaAs and its applications. MRS Proc, 1993, 319, P. 93.

[6] Marshall E.D., Zhang B., Wang L.C., Jiao P.F., Chen W.X., Sawada T., Lau S.S., Kavanagh K.L. and Kuech T.F. Nonalloyed ohmic contacts to n-GaAs by solid-phase epitaxy of Ge. J. Appl. Phys, 1987, 62(3), P. 942-947.

[7] Lin C., Lee C.P. Comparison of $\mathrm{Au} / \mathrm{Ni} / \mathrm{Ge}, \mathrm{Au} / \mathrm{Pd} / \mathrm{Ge}$, and $\mathrm{Au} / \mathrm{Pt} / \mathrm{Ge}$ Ohmic contacts to n-type GaAs. J. Appl. Phys, 1990, 67(1), P. 260-263.

[8] Hao P.H., Wang L.C., Deng F., Lau S.S., Cheng J.Y. On the low resistance Au/Ge/Pd ohmic contact to n-GaAs. J. Appl. Phys, 1996, 79(8), P. 4211-4215.

[9] Wang L.C., Hao P.H., Cheng J.Y., Deng F., Lau S.S. Ohmic contact formation mechanism of the Au/Ge/Pd/n-GaAs system formed below $200{ }^{\circ}$ C. J. Appl. Phys, 1996, 79(8), P. 4216-4220.

[10] Berger H.H. Contact Resistance and Contact Resistivity. J. Electrochem. Soc, 1972, 119(4), P. $507-514$.

[11] Pahanov N.A., Andreev V.M., Shvartz M.Z., Phelyakov O.P. Modern Architectures and Technologies of High-efficienct Solar Cells in III-V Heterostructures for Space and Ground Applications. Autometria, 2018, 54(2), P. 93-112.

[12] Orru M., Piazza V., Rubini S., Roddaro S. Rectification and Photoconduction Mapping of Axial Metal-Semiconductor Interfaces Embedded in GaAs Nanowires. Phys. Rev. Appl, 2015, 4, 44010. 